\title{
Montessori Early Childhood Teacher Perceptions of Family Priorities and Stressors
}

\author{
Ann Epstein $\dagger$ \\ University of Wisconsin-La Crosse
}

\section{ACKNOWLEDGEMENT}

Statistical analysis provided Dr. Dave Reineke (Director) and Jake Linnabary (Student Consultant), University of Wisconsin - La Crosse Statistical Consulting Center.

KEYWORDS. Montessori, teacher-family partnerships, early childhood teacher perceptions, family priorities, family stressors

\begin{abstract}
Teachers of young children work closely with families. One component of teacher-family partnerships is teachers' understanding of family priorities and stressors. This study examines Montessori Early Childhood (ages three through six) teacher perceptions of family priorities and stressors through an analysis of responses to two parallel surveys. Eighty teachers (37\% of those who received the survey) and 49 family members (representing a 55\% response rate) completed surveys. Significant differences were found between teachers' perceptions of five (of seven) family priorities and families' actual responses. Teachers anticipated that families would rank "making academic progress" as families' highest priority. However, families reported that "developing kindness" is the most important priority for their young children. No significant differences were found when comparing teacher rankings of family stressors with actual family responses. Montessori Early Childhood teachers ranked "not having enough time" as the most stressful of six possible family stressors. Families confirmed that time pressures cause them the most stress. Montessori's recommendations for teachers and families are summarized. Recommendations for building stronger family partnerships in the context of Montessori's philosophy_-for example, ongoing self-reflection-are provided.
\end{abstract}

Effective family-teacher partnerships are essential for student achievement across all age levels (Carr, 2011). They are particularly crucial for the optimal development of young children (Arndt \& McGuire-Schwartz, 2008; Knopf \& Swick, 2007). When teachers and families work together to address day-to-day challenges, they are more likely to trust one another and provide consistent, nurturing environments for young children (Gestwicki, 2007; Swick, 2004). 


\section{Montessori Philosophy Regarding Teacher-Family Collaboration}

While Montessori specifies clear roles for teachers and parents (Montessori, 1923/1970), family-teacher collaboration is not a central component of her philosophy. Instead, Montessori centered her curriculum and her philosophy squarely on the child and the preparation of the teacher. She urged both families and teachers to honor each individual child's potential for growth and development. For example, the first two chapters of Montessori's The Child, Society and the World (one of several volumes of her unpublished speeches and writings reprinted in 1995) are addressed to first parents and then teachers. Montessori implored both sets of adults to respect children's inner drive to explore their surroundings in a safe manner. She instructed parents to refrain from constant questioning (e.g., "Why are you doing that?") but instead watch for children's interests and then provide opportunities for those pursuits. Montessori instructed teachers to purposefully design environments with activities that engage children in independent learning that is characterized by their interests and their emerging abilities to concentrate. While providing clear dos and don'ts for each, she held teacher-child and parent-child interactions as separate components of children's learning and growth.

In contrast, the National Association for the Education of Young Children posits "establishing reciprocal relationships with parents" as a key area of developmentally appropriate practice (Copple \& Bredekamp, 2009, p. 16). The Public Affairs Committee of the Association for Childhood Education International (Zygmunt-Fillwalk \& Woods, 2007) and the Division for Early Childhood of the Council for Exceptional Children (Grisham-Brown \& Pretti-Frontczak, 2011) also asserts the vital role of teacher-family collaboration at the early childhood level. The American Montessori Society, the Montessori Foundation, and the North American Montessori Teachers' Association websites all provide resources for families and encourage family-teacher communication. These professional organizations uphold the central Montessori principle of honoring each individual child's growth. They also promote the necessity of building effective relationships with the adults who guide children's development.

Teacher perceptions of families' priorities for their young children and of stressors that impact families who are raising young children affect family-teacher collaboration. Teacher recognition of what is important and what is worrisome for families could lead to an informed understanding and appreciation of parenting styles. Understanding, rather than assuming, families' priorities and areas of stress could assist teachers in providing effective learning experiences for each child (Knopf \& Swick, 2007; Guo, 2015). Current research regarding family priorities and stressors is reviewed in the context of teacher-family partnerships.

\section{Family Priorities}

While no research was found regarding Montessori teacher-family collaboration, several early childhood researchers have addressed this relationship. Hauser-Cram, Sirin, and Stipek (2003) emphasized the importance of securing a clear and accurate understanding of family priorities regarding young children's education, particularly for families with low incomes. A mixed-methods study by Reedy and McGrath (2010) revealed difficulties stemming from both verbal and written communications in child care centers. Relationships became strained when opinions regarding priorities differed, particularly if information was not received or sent promptly.

\section{Family Stressors}

Whereas relatively little research was found regarding family priorities, numerous studies have addressed family stressors. Finances, diversity, family member challenges (e.g., single parenting, caring for elderly parents), children's behaviors, lack of time, and addressing academic expectations reportedly result in stress to families of young children. 
Today's teachers and parents are teaching and parenting within what appears to be an unstable economy in the U.S. and across some European nations. The State of Working America (12th edition), published by the Economic Policy Institute, reported that the struggle of working families to find steady employment with adequate salaries is a particularly stressful challenge for low- to middle-income families (Mishel, Bivens, Gould, \& Shierholz, 2012). While middle- and high-income families had sufficient finances for the short term, they worried about job stability and experienced anxiety related to ongoing expenses (James, Brown, Goodsell, Stovall, \& Flaherty, 2010).

As Montessori classrooms become more diverse, a clear understanding of cultural differences among families is a necessity (Durand, 2010). Challenges exist for both teachers and families. Some teachers felt inadequate and unprepared to collaborate with families who had different child-rearing customs (Eberly, Joshi, \& Konzal, 2007). Some families expressed confusion as they experienced differing cultural practices related to child-rearing (Cho, Chen, \& Shin, 2010; Winterbottom, 2013).

Relationships among members can be a source of stress in families with young children. Examples of possible stressors include caring for elderly parents or grandparents, marital discord, and sibling rivalry. Attending to the needs of young children was found to be especially stressful for single parents (Waldfogel, Craigie, \& Brooks-Gunn, 2010). Stress could intensify for parents rushing to meet the ongoing needs of young children (Boger, Tompson, Briggs-Gowan, Pavlis, \& Carter, 2008).

Parenting young children involves guiding both behavior and learning. Setting limits and providing appropriate guidance can be stressful for some families, particularly if cultural expectations differ from home to school (Gonzalez-Mena \& Shareef, 2005). Many families are attracted to Montessori education's rich, deep curriculum. Some, though, were stressed and anxious about academic components of their child's learning (Hauser-Cram et al., 2003).

Addressing these stressors as well as family priorities requires strong partnerships between parents and teachers. Mutual understanding of family priorities and stressors can strengthen communication and build collaborative partnerships. One way to investigate family-teacher collaboration is to explore alignment between teacher perceptions of family views and families' actual statements. Teacher perceptions of family priorities and stressors are addressed in this study by examining two questions. Do Montessori teacher perceptions of family priorities regarding Early Childhood education align with family statements of their goals? And do Montessori teacher perceptions of family stressors regarding child raising and family life align with family statements of these stressors?

A review of research and Montessori practices resulted in identification of the following indicators to examine alignment between teacher perceptions and family statements: learning to behave appropriately, making academic progress, making friends, learning to be kind and respectful, financial challenges, finding adequate time to care for young children, providing opportunities to express individual creativity, adjusting to a different culture and/or language, and addressing family issues (for example, issues related to marital problems, single parenting, and extended family).

\section{Methodology and Participants}

The findings presented here are part of a larger investigation of teachers' perceptions of how Montessori education affects children's learning and development as well as parenting issues. The goal of this particular analysis was to discover if Montessori teachers' perceptions and actual family statements of priorities and stressors align.

A between-subject design was employed to compare Montessori teacher and family responses to parallel survey questions regarding family priorities and stressors. The survey was 
emailed to 218 Montessori Early Childhood teachers and 89 parents of children in Montessori programs across the United States. Teachers and families were not from the same schools. Eighty teachers $(37 \%)$ and 49 family members $(55 \%)$ completed the survey. Teachers stated that $6 \%$ of their families had low incomes, 56\% had middle incomes, and 38\% had high incomes. Families were not asked to share income levels. They provided the following information regarding education levels: Bachelor's degree, 38\%; Master's degree, 39\%; advanced degree, 17\%.

Teachers and families provided similar responses regarding school settings. Six percent of teachers and $3 \%$ of families selected "rural," $58 \%$ of teachers and $59 \%$ of families selected "suburban," and $36 \%$ of teachers and $38 \%$ of families selected "urban" when asked to indicate school settings.

Teachers completed a 26-item survey composed of six demographic questions, 15 Likertscale or yes/no questions, two forced-rating questions (the focus of this article), and three openended questions (see Supplemental Documents for full teacher survey). Family members completed a parallel survey containing four demographic questions, 14 Likert-scale or yes/no items, two forced-rating questions (the focus of this article), and three open-ended questions (see Appendix B for full family survey). The two forced-rating questions addressed teachers' perceptions of seven family priorities and six family stressors.

All participants (teachers and family members) volunteered to be members of a panel facilitated by the Research Committee of the American Montessori Society. The researcher applied for and was granted permission to invite panel members to answer survey questions. Permission included approval by the researcher's institutional review board. Informed consent was achieved through survey responses.

Teachers' perceptions of family priorities and stressors were ranked as high, medium, or low by adding the top, middle, and bottom responses to the two forced-rating survey items. Family statements of their priorities were ranked in the same way (high, medium, or low by adding top, middle, and bottom responses). Percentages were calculated for each response.

Chi-square analysis was used to compare the distributions of the grouped rankings for families and teachers. The four conditions for using Mann-Whitney analysis were addressed by the study's between-subject design comparing family and teacher responses, independent completion of surveys by the participants, ordinal responses to survey questions (higher or lower ratings by families or teachers), and the presence of two levels within the independent variable (family and teacher survey responses).

\section{Results}

\section{Priorities}

Teachers were asked to rank order a list of seven family priorities for young children. Combining teachers' first and second selections revealed that 53\% ranked "making academic progress" as families' top priority (see Table 1). Teachers ranked "learning to behave appropriately" as families' second priority. Combining teachers' sixth and seventh selections revealed that $66 \%$ ranked "having opportunities to be creative" as the lowest family priority. Teachers placed "making friends," "assuring children have adequate materials," "learning to be kind," and "learning to be respectful" as midlevel priorities for families.

In contrast, $50 \%$ of families ranked "learning to be kind" and $42 \%$ ranked "learning to be respectful" as their top two priorities. Families ranked "making sure my child has adequate materials" (71\%), "making academic progress" (39\%), and "having opportunities to be creative" (also 39\%) as low priorities. They placed "guiding appropriate behaviors" and "making friends" in 
the middle of their priorities for young children. A comparison of teacher and family rankings by groups (high, medium, and low priorities) is presented in Table 2.

Table 1

Distribution of Ranks Given by Families and Teachers for Family Priorities

\begin{tabular}{|c|c|c|c|c|c|c|c|c|c|}
\hline \multirow[b]{2}{*}{ Family Priority } & & \multicolumn{7}{|c|}{ Rank } & \multirow[b]{2}{*}{$n$} \\
\hline & & 1 & 2 & 3 & 4 & 5 & 6 & 7 & \\
\hline \multirow{2}{*}{$\begin{array}{l}\text { Learning to } \\
\text { behave } \\
\text { appropriately }\end{array}$} & $\begin{array}{l}\text { Families } \\
(3)^{* *}\end{array}$ & 16.3 & 24.5 & 22.4 & 14.3 & 10.2 & 10.2 & 2.0 & 49 \\
\hline & $\begin{array}{l}\text { Teachers } \\
\text { (2) }\end{array}$ & 18.8 & 27.5 & 25.0 & 10.0 & 12.5 & 6.3 & 0.0 & 80 \\
\hline \multirow[t]{2}{*}{$\begin{array}{l}\text { Making academic } \\
\text { progress* }\end{array}$} & $\begin{array}{l}\text { Families } \\
\text { (5) }\end{array}$ & 6.1 & 14.3 & 10.2 & 12.2 & 18.4 & 22.4 & 16.3 & 49 \\
\hline & $\begin{array}{l}\text { Teachers } \\
\text { (1) }\end{array}$ & 45.0 & 13.8 & 12.5 & 12.5 & 6.3 & 7.5 & 2.5 & 80 \\
\hline \multirow[t]{2}{*}{ Making friends* } & $\begin{array}{l}\text { Families } \\
\text { (7) }\end{array}$ & 4.1 & 4.1 & 12.2 & 36.7 & 26.5 & 16.3 & 0.0 & 49 \\
\hline & $\begin{array}{l}\text { Teachers } \\
\text { (3) }\end{array}$ & 7.5 & 30.0 & 21.3 & 21.3 & 8.8 & 7.5 & 3.8 & 80 \\
\hline \multirow[t]{2}{*}{$\begin{array}{l}\text { Learning to be } \\
\text { kind* }\end{array}$} & $\begin{array}{l}\text { Families } \\
\text { (1) }\end{array}$ & 36.7 & 14.3 & 26.5 & 12.2 & 6.1 & 2.0 & 2.5 & 49 \\
\hline & $\begin{array}{l}\text { Teachers } \\
\text { (5) }\end{array}$ & 6.3 & 0.0 & 11.3 & 27.5 & 28.7 & 13.8 & 2.0 & 80 \\
\hline \multirow{2}{*}{$\begin{array}{l}\text { Making sure my } \\
\text { child has adequate } \\
\text { materials }\end{array}$} & $\begin{array}{l}\text { Families } \\
\text { (4) }\end{array}$ & 16.3 & 6.1 & 0.0 & 2.0 & 4.1 & 12.2 & 69.2 & 49 \\
\hline & $\begin{array}{l}\text { Teachers } \\
\text { (4) }\end{array}$ & 16.3 & 3.8 & 7.5 & 5.0 & 3.8 & 15.0 & 48.8 & 80 \\
\hline \multirow{2}{*}{$\begin{array}{l}\text { Having } \\
\text { opportunities } \\
\text { to be creative* }\end{array}$} & $\begin{array}{l}\text { Families } \\
\text { (6) }\end{array}$ & 6.1 & 8.2 & 12.2 & 12.2 & 22.4 & 24.5 & 14.3 & 49 \\
\hline & $\begin{array}{l}\text { Teachers } \\
\text { (7) }\end{array}$ & 1.3 & 2.5 & 7.5 & 8.8 & 13.8 & 35.0 & 31.3 & 80 \\
\hline \multirow[t]{2}{*}{$\begin{array}{l}\text { Learning to be } \\
\text { respectful* }\end{array}$} & $\begin{array}{l}\text { Families } \\
\text { (2) }\end{array}$ & 14.3 & 28.6 & 16.3 & 10.2 & 12.2 & 12.2 & 6.1 & 49 \\
\hline & $\begin{array}{l}\text { Teachers } \\
\text { (6) }\end{array}$ & 5.0 & 12.5 & 15.0 & 15.0 & 26.3 & 15.0 & 11.3 & 80 \\
\hline
\end{tabular}

* Distributions of grouped rankings for priorities for families and teacher perceptions of families are significantly different at the overall level of significance of .05. (The $p$ value for each of these is less than the Bonferroni-adjusted level of significance of $0.05 / 7 \approx 0.00714$.)

** Overall rank based on the sum of the 1 and 2 (of 7) rankings. 
Table 2

Distributions of Grouped Ranks Given by Families and Teachers for Perceived Family Priorities

\begin{tabular}{|c|c|c|c|c|c|}
\hline \multirow{2}{*}{ Priority } & & \multicolumn{3}{|c|}{ Rank } & \multirow[b]{2}{*}{$n$} \\
\hline & & $\operatorname{High}(1-2)$ & Medium (3-5) & Low (6-7) & \\
\hline \multirow{2}{*}{$\begin{array}{l}\text { Learning to behave } \\
\text { appropriately }\end{array}$} & Family & $40.8 \%$ & $46.9 \%$ & $12.2 \%$ & 49 \\
\hline & Teacher & $46.3 \%$ & $47.5 \%$ & $6.3 \%$ & 80 \\
\hline \multirow{2}{*}{$\begin{array}{l}\text { Making academic } \\
\text { progress* }\end{array}$} & Family & $20.4 \%$ & $40.8 \%$ & $38.8 \%$ & 49 \\
\hline & Teacher & $58.8 \%$ & $31.3 \%$ & $10.0 \%$ & 80 \\
\hline \multirow[t]{2}{*}{ Making friends* } & Family & $8.2 \%$ & $75.5 \%$ & $16.3 \%$ & 49 \\
\hline & Teacher & $37.5 \%$ & $51.2 \%$ & $11.3 \%$ & 80 \\
\hline \multirow[t]{2}{*}{ Learning to be kind* } & Family & $51.0 \%$ & $44.9 \%$ & $4.1 \%$ & 49 \\
\hline & Teacher & $16.3 \%$ & $67.5 \%$ & $16.3 \%$ & 80 \\
\hline \multirow{2}{*}{$\begin{array}{l}\text { Making sure children have } \\
\text { adequate materials }\end{array}$} & Family & $22.4 \%$ & $6.1 \%$ & $71.4 \%$ & 49 \\
\hline & Teacher & $20.0 \%$ & $16.3 \%$ & $63.7 \%$ & 80 \\
\hline \multirow{2}{*}{$\begin{array}{l}\text { Having opportunities to } \\
\text { express individual } \\
\text { creativity* }\end{array}$} & Family & $14.3 \%$ & $46.9 \%$ & $38.8 \%$ & 49 \\
\hline & Teacher & $3.8 \%$ & $30.0 \%$ & $66.3 \%$ & 80 \\
\hline \multirow{2}{*}{ Learning to be respectful* } & Family & $42.9 \%$ & $38.8 \%$ & $18.4 \%$ & 49 \\
\hline & Teacher & $17.5 \%$ & $56.3 \%$ & $26.3 \%$ & 80 \\
\hline
\end{tabular}

*Distributions of grouped rankings for priorities for families and teacher perceptions of families are significantly different at the overall level of significance of 0.05 . (The $p$ value for each of these is less than the Bonferroni-adjusted level of significance of $.05 / 7 \approx 0.00714$.)

Families ranked "learning to be kind," "having opportunities to express individual creativity," and "learning to be respectful" significantly higher than did teachers (see Table 3 for Mann-Whitney mean ranks comparisons). Teachers ranked "making academic progress" and "making friends" significantly higher than did families. Significant differences in the distributions of teacher perceptions and actual family statements for the following five (of seven) priorities were also established through chi-square testing: "making academic progress," $\chi^{2}(2,129)=22.929, p$ $=.476$; "making friends," $\chi^{2}(2,129)=13.475, p=.001$; "learning to be kind," $\chi^{2}(2,129)=$ $18.967, p<.01$; "having opportunities to be creative," $\chi^{2}(2,129)=10.854, p=.004$; and "learning to be respectful," $\chi^{2}(2,129)=9.884, p=.007$ (see Table 4 for full chi-square analysis). 
Table 3

Comparison of Ranks for Family Priorities Given by Montessori Teachers and Parents Using MannWhitney Tests

\begin{tabular}{lccrr}
\hline Family Priority & $\begin{array}{c}\text { Mean Rank } \\
\text { Teacher }\end{array}$ & $\begin{array}{c}\text { Mean Rank } \\
\text { Parents }\end{array}$ & $z$ & \multicolumn{1}{c}{$p$} \\
\hline Learning to behave appropriately & 62.83 & 68.54 & -0.860 & .390 \\
Making academic progress* & 51.26 & 87.43 & -5.437 & $<.001$ \\
Making friends* & 55.23 & 80.95 & -3.869 & .001 \\
Learning to be kind* & 78.86 & 42.38 & 5.466 & $<.001$ \\
Making sure my child has adequate & 62.76 & 68.65 & -0.944 & .345 \\
materials & & & & \\
Having opportunities to be creative* & 72.98 & 51.97 & 3.182 & .001 \\
Learning to be respectful* & 72.41 & 52.91 & 2.913 & .004 \\
\hline
\end{tabular}

*Mean ranks for family priorities and teacher perceptions of family priorities are significantly different at Bonferroni-adjusted alpha levels of .007 per test $(.05 / 7)$.

Table 4

Comparison of Grouped Ranks for Family Priorities Given by Montessori Teachers and Parents Using Chi-Square Tests

\begin{tabular}{lrrr}
\hline Family Priority & $\chi^{2}$ & df & \multicolumn{1}{c}{$p$} \\
\hline Learning to behave appropriately & 1.486 & 2 & .476 \\
Making academic progress* & 22.929 & 2 & $<.001$ \\
Making friends* & 13.475 & 2 & .001 \\
Learning to be kind* & 18.976 & 2 & $<.010$ \\
Making sure my child has adequate materials & 2.869 & 2 & .238 \\
Having opportunities to be creative* & 10.854 & 2 & .004 \\
Learning to be respectful* & 9.884 & 2 & .007 \\
\hline
\end{tabular}

*Distributions of grouped ranking for family priorities and teacher perceptions of family priorities are significantly different at Bonferroni-adjusted alpha levels of .007 per test $(0.05 / 7)$.

\section{Stressors}

Teachers' perceptions of family stressors compared favorably with family statements. When teachers' perceptions of family stressors were compared with actual family statements, no significant differences were found. Both teachers and families ranked "not enough time" as the most stressful of six possible stressors (see Table 5). Teachers and families ranked economic stressors, behavioral challenges, and academic challenges as midlevel stressors, with slight differences in rank. Both teachers and families ranked family challenges and adjusting to a culture and/or language as low stressors. No significant differences were found between teacher perceptions and family statements of stressors using Mann-Whitney tests (see Table 6). Grouped rankings (high, medium, and low) further illustrate similarities between teacher perceptions of family stressors and actual family rankings of stressors (see Table 7). Similarly, no significant differences were found in the distributions of grouped rankings using chi-square tests (see Table $8)$. 
Table 5

Distribution of Ranks Given by Families and Teachers for Family Stressors

\begin{tabular}{|c|c|c|c|c|c|c|c|c|}
\hline Family Stressor & & 1 & 2 & 3 & 4 & 5 & 6 & $n$ \\
\hline \multirow[t]{2}{*}{$\begin{array}{l}\text { Economic } \\
\text { challenges }\end{array}$} & $\begin{array}{l}\text { Families } \\
(2)^{*}\end{array}$ & 26.5 & 16.3 & 8.2 & 20.4 & 18.4 & 10.2 & 49 \\
\hline & $\begin{array}{l}\text { Teachers } \\
\text { (3) }\end{array}$ & 25.0 & 20.0 & 8.8 & 18.8 & 13.8 & 13.8 & 80 \\
\hline \multirow{2}{*}{$\begin{array}{l}\text { Academic } \\
\text { performance } \\
\text { expectations }\end{array}$} & $\begin{array}{l}\text { Families } \\
\text { (3) }\end{array}$ & 6.1 & 20.4 & 32.7 & 20.4 & 14.3 & 6.1 & 49 \\
\hline & $\begin{array}{l}\text { Teachers } \\
\text { (4) }\end{array}$ & 11.3 & 22.5 & 23.8 & 25.0 & 15.0 & 2.5 & 80 \\
\hline \multirow[t]{2}{*}{$\begin{array}{l}\text { Behavioral } \\
\text { expectations }\end{array}$} & $\begin{array}{l}\text { Families } \\
\text { (4) }\end{array}$ & 16.3 & 28.6 & 22.4 & 26.5 & 4.1 & 2.0 & 49 \\
\hline & $\begin{array}{l}\text { Teachers } \\
\text { (2) }\end{array}$ & 15.5 & 17.5 & 25.0 & 26.3 & 15.0 & 1.3 & 80 \\
\hline \multirow[t]{2}{*}{ Not enough time } & $\begin{array}{l}\text { Families } \\
\text { (1) }\end{array}$ & 34.7 & 22.4 & 14.3 & 10.2 & 18.4 & 0.0 & 49 \\
\hline & $\begin{array}{l}\text { Teachers } \\
\text { (1) }\end{array}$ & 42.5 & 22.5 & 15.0 & 3.8 & 11.3 & 5.0 & 80 \\
\hline \multirow{2}{*}{$\begin{array}{l}\text { Adjusting to a } \\
\text { culture and/or } \\
\text { language }\end{array}$} & $\begin{array}{l}\text { Families } \\
\text { (6) }\end{array}$ & 0.0 & 4.1 & 2.0 & 10.2 & 8.2 & 75.5 & 49 \\
\hline & $\begin{array}{l}\text { Teachers } \\
\text { (6) }\end{array}$ & 0.0 & 0.0 & 6.3 & 7.5 & 26.3 & 60.0 & 80 \\
\hline \multirow[t]{2}{*}{ Family challenges } & $\begin{array}{l}\text { Families } \\
\text { (5) }\end{array}$ & 16.3 & 8.2 & 20.4 & 12.2 & 36.7 & 6.1 & 49 \\
\hline & $\begin{array}{l}\text { Teachers } \\
\text { (5) }\end{array}$ & 6.3 & 17.5 & 21.3 & 18.8 & 18.8 & 17.5 & 80 \\
\hline
\end{tabular}

Note. Distributions of grouped rankings for stressors for families and teacher perceptions of families are not significantly different at the overall level of significance of 0.05 . (The $p$ value for each of these is not less than the Bonferroni-adjusted level of significance of $0.05 / 7 \approx 0.007$.)

* Overall rank based on the sum of the 1 and 2 (of 7) rankings.

Table 6

Comparison of Ranks for Family Stressors Given by Montessori Teachers and Parents Using MannWhitney Tests

\begin{tabular}{lccrc}
\hline Family Stressor & $\begin{array}{c}\text { Mean Rank } \\
\text { Teacher }\end{array}$ & $\begin{array}{c}\text { Mean Rank } \\
\text { Families }\end{array}$ & \multicolumn{1}{c}{$\mathrm{z}$} & $p$ \\
\hline Economic challenges & 64.99 & 65.02 & -0.005 & .996 \\
Academic performance expectations & 63.52 & 67.42 & -0.589 & .556 \\
Behavioral expectations & 68.62 & 59.08 & 1.442 & .149 \\
Not enough time & 62.76 & 68.65 & -0.905 & .365 \\
Adjusting to a culture and/or language & 61.99 & 69.91 & -1.389 & .165 \\
Family challenges & 66.05 & 63.29 & 0.415 & .679 \\
\hline
\end{tabular}

Note. Mean ranks for family stressors and teacher perceptions of family stressors are not significantly different at Bonferroni-adjusted alpha levels of .008 per test $(0.05 / 6)$. 
Table 7

Distribution of Grouped Ranks Given by Families and Teachers for Perceived Family Stressors

\begin{tabular}{|c|c|c|c|c|c|}
\hline \multirow{2}{*}{\multicolumn{2}{|c|}{ Stressor* }} & \multicolumn{3}{|c|}{ Rank } & \multirow[b]{2}{*}{$n$} \\
\hline & & High (1-2) & Medium (3-4) & Low (5-6) & \\
\hline \multirow{2}{*}{ Economic challenges } & Family & $42.9 \%$ & $28.6 \%$ & $28.6 \%$ & 49 \\
\hline & Teacher & $45.0 \%$ & $27.5 \%$ & $27.5 \%$ & 80 \\
\hline \multirow{2}{*}{$\begin{array}{l}\text { Academic performance } \\
\text { expectations }\end{array}$} & Family & $26.5 \%$ & $53.1 \%$ & $20.4 \%$ & 49 \\
\hline & Teacher & $33.8 \%$ & $48.8 \%$ & $17.5 \%$ & 80 \\
\hline \multirow[t]{2}{*}{ Behavioral expectations } & Family & $44.9 \%$ & $49.0 \%$ & $6.1 \%$ & 49 \\
\hline & Teacher & $32.5 \%$ & $51.2 \%$ & $16.3 \%$ & 80 \\
\hline \multirow[t]{2}{*}{ Not enough time } & Family & $57.1 \%$ & $24.5 \%$ & $18.4 \%$ & 49 \\
\hline & Teacher & $65.0 \%$ & $18.8 \%$ & $16.3 \%$ & 80 \\
\hline \multirow{2}{*}{$\begin{array}{l}\text { Adjusting to a different } \\
\text { culture and/or language }\end{array}$} & Family & $4.1 \%$ & $12.2 \%$ & $83.7 \%$ & 49 \\
\hline & Teacher & $0.0 \%$ & $13.8 \%$ & $86.3 \%$ & 80 \\
\hline \multirow{2}{*}{$\begin{array}{l}\text { Family challenges (e.g., } \\
\text { marital problems, } \\
\text { extended family issues, } \\
\text { etc.) }\end{array}$} & Family & $24.5 \%$ & $32.7 \%$ & $42.9 \%$ & 49 \\
\hline & Teacher & $23.8 \%$ & $40.0 \%$ & $36.3 \%$ & 80 \\
\hline
\end{tabular}

*No distributions of grouped rankings for teacher perceptions of family stressors are significantly different at the overall level of significance of 0.05. (None of these had a $p$ value less than the Bonferroni-adjusted level of significance of $0.05 / 6 \approx 0.008$.)

Table 8

Comparison of Grouped Ranks for Family Stressors Given by Montessori Teachers and Parents Using Chi-Square Tests

\begin{tabular}{lccc}
\hline Family Stressor & $\chi^{2}$ & $\mathrm{df}$ & $p$ \\
\hline Economic challenges & 0.057 & 2 & .972 \\
Academic performance expectations & 0.761 & 2 & .684 \\
Behavioral expectations & 3.799 & 2 & .150 \\
Not enough time & 0.861 & 2 & .650 \\
Adjusting to a culture and/or language & 3.341 & 2 & .188 \\
Family challenges & 0.790 & 2 & .674 \\
\hline
\end{tabular}

*Distributions of grouped ranking for family stressors and teacher perceptions of family stressors are significantly different at Bonferroni-adjusted alpha levels of .008 per test (0.05/6).

Note. Zero values were present for "adjusting to a culture and/or language." Fisher's exact test was run, resulting in a similar $p$ value (.233).

\section{Discussion}

\section{Limitations}

Study participants (teachers and family members) were members of a research panel developed by the Research Committee of the American Montessori Society. The panel provides researchers with a national pool of survey participants from varying backgrounds (such as urban, rural, experienced, and newcomers to Montessori). Varied backgrounds raise questions that are not 
addressed in this analysis. For example, do Montessori teachers who teach in urban settings perceive family priorities differently than teachers who are in rural communities? Do families with diverse backgrounds (e.g., socioeconomic, language, ethnicity, children's special needs) rate stressors differently than families from majority populations?

Participants were not matched. Teachers did not rank priorities and stressors of the families in their own schools. While aggregating data from a national pool provides generalizable results, it does not provide a true picture of teachers' perceptions of the specific families they partner with every day.

\section{Nonalignment Regarding Priorities}

Responses regarding family priorities reveal a disconnection between what teachers believe families consider important and what families actually state is important. Families of young children hold learning to be kind and to be respectful as their top two priorities. A strong majority of teachers (53\%) selected "making academic progress" as families' most important priority. Families ranked this priority fifth, in the bottom half of their priorities. These statistically significant responses suggest that teachers do not have an accurate sense of family priorities. This misunderstanding can result in an emphasis on academic lessons and not as much attention on developing character traits such as kindness and respect.

This disconnection is not surprising. Family collaboration (communicating and engaging with families) emerged as the most challenging aspect of teaching, as a MetLife survey of 1,001 public school teachers showed (MetLife, Inc., 2006). In a study of early childhood teacher efficacy, communicating with families emerged as the only area of seven teaching components in which teachers did not express confidence (Epstein \& Willhite, 2015). While neither study addressed Montessori family-teacher collaboration, the studies do indicate difficulties teachers have relating to and connecting with their families.

A case study of multicultural teacher-family communication offers insight regarding family perspectives (Guo, 2015). Parents of a 4-year-old boy shared that they were disappointed their child's teacher did not challenge him. When asked to elaborate about conversations with his teachers, the parents provided the following description, "We talk to the teachers (about) good things or ask some harmless questions. They are friendly but we have never opened ourselves to them so there is no trouble. We are happy about Dupa's days here. He's happy so we are fine" (Guo, 2015, p. 68).

The family had specific concerns regarding their child's learning opportunities, but they declined to share these with his teachers. They did not want to cause trouble, even though their child's teachers did not recognize their priorities, and as a result, their child was not learning to the degree they believed he could.

\section{Alignment Regarding Stressors}

In contrast to a lack of alignment regarding priorities, survey responses suggest that Montessori Early Childhood teachers have an accurate sense of family stressors. Teachers selected "not having enough time" as the most stressful of six stressors. Families confirmed that this is indeed more stressful than (in order from next most stressful to least stressful) economic challenges, academic performance expectations, behavioral expectations, adjusting to a new culture and/or language, or family challenges (Table 5). Teacher understanding of stressors is reassuring in view of ongoing societal and within-family challenges. Additional research could shed light on why teachers appear to understand family stressors but not family priorities.

Summer and Summer (2014) describe effective teacher-family collaboration in the form of purposeful conversations with families regarding children's interests. For example, families noted 
science as an area of interest for their children. Teachers then sent home photos of a green insect that children found on the playground. Families embarked on conversations with their children that led to further investigations at school.

A sharing of cultural traditions occurred following a teacher-parent conversation regarding stressors (Summer \& Summer, 2014). A parent shared that her child was worried about a long plane trip to India for a family wedding. The teacher provided children's books about air travel in the classroom. She also talked about her own upcoming wedding; this conversation resulted in the teacher and the family sharing wedding traditions.

\section{Suggestions for Further Research and Implications for Practice}

This study examined Montessori teacher perceptions of family priorities and stressors using two parallel surveys (one completed by teachers and one completed by parents). Analysis of additional survey responses is needed to explore if or how the Montessori approach to education supports families in addressing priorities and stressors. Additional analysis is also needed to investigate the larger question of if or how the Montessori approach to education supports teacher/family partnerships.

It is not known if most of the families were affluent, had moderate incomes, or struggled with low incomes. Families ranked providing their children with adequate materials as a low priority, but they ranked economic concerns as a high stressor (next most stressful after "not enough time"). Further research regarding correlations between family incomes and priorities and stressors could perhaps help teachers better understand individual family circumstances.

It is important to note that both teachers and parents volunteered to participate in this survey research. They provided contact information (email addresses) to the American Montessori Society's Research Panel and then consented to respond to the survey. Response rates were high for both groups (37\% for teachers and 55\% for parents). However, it is quite possible that both groups, parents in particular, are fairly strong Montessori advocates. Parents who are less engaged may have different responses. Similarly, a randomly selected group of teachers may provide more varied responses.

Findings from the current analysis point to the need for teachers to understand family priorities. Montessori teachers typically talk with individual families about their priorities during the enrollment process. Usually this conversation is quite brief. Families may indicate their priorities on a checklist that is reviewed by the head/principal but perhaps not by the child's teacher. Unless there is a major concern or crisis, family priorities may not be addressed. Family priorities often come into focus when a misunderstanding occurs. Learning about family priorities in the context of a problem (or worse, a crisis) is quite different from developing an accurate understanding of today's families in their everyday world.

Simply asking families about their priorities is the first step in building strong partnerships. Patton (2015) encouraged Montessori teachers to carry out this conversation during home visits. A discussion of children's interests and family expectations in the child's home can start the process of building trusting relationships.

Developing collaborative partnerships certainly requires purposeful conversations regarding family priorities and stressors. However, inward reflection is perhaps more important. Teachers need to ask and then honestly answer questions regarding how they relate to families. Knopf and Swick (2008) suggested teachers ask "What are my dispositions related to working with families? How do I communicate and interact with the families of the children I teach? How can I strengthen the family understanding and family involvement processes I use?" (p. 426). Regular self-checks regarding communications can assist teachers in finding and then implementing effective ways to partner with families. 
A commitment to ongoing reflection about family partnerships is particularly important for teachers who (in accordance with Montessori's advice) focus on each child's learning process and the preparation of the environment. These are both critical; however, optimal child learning can occur only when family voices are honored. Guo (2015) pointed out that, while children form identities through interactions with school peers and with teachers, the heart and soul of this formation occurs within family relationships. Her observation suggests a third addition to Montessori's two instructions for Early Childhood teachers. Building and maintaining effective family partnerships, along with honoring each individual child's learning potential and preparing the environment, are needed for optimal learning. Montessori teachers can begin building partnerships by understanding family priorities and stressors. In this way, building on Dr. Montessori's appeal to teachers, they will be following the child in the family.

\section{ASSOCIATED CONTENT}

Supporting Information. The survey instruments used in this study are available as supporting documentation free of charge via the Internet at https://journals.ku.edu/index.php/jmr/index.

\section{AUTHOR INFORMATION}

\section{+Corresponding Author}

Ann Epstein is an assistant professor and director of the Early Childhood - Middle Childhood program at the University of Wisconsin - La Crosse in the Department of Educational Studies. She can be reached at aepstein@uwlax.edu.

\section{References}

Arndt, J., \& McGuire-Schwartz, M. E. (2008). Early childhood school success: Recognizing families as integral partners. Childhood Education, 84(5), 281-285. doi: $10.1080 / 00094056.2008 .10523025$

Boger, K. D., Tompson, M. C., Briggs-Gowan, M. J., Pavlis, L. E., \& Carter, A. S. (2008). Parental expressed emotion toward children: Prediction from early family functioning. Journal of Family Psychology, 22(5), 784-788. doi: 10.1037/a0013251

Carr, N. (2011). Community engagement is vital. American School Board Journal, 198(3), 38-39.

Cho, E. K., Chen, D. W., \& Shin, S. (2010). Supporting transnational families. Young Children, (65) 4, 30-37.

Copple, C., \& Bredekamp, S. (Eds.). (2009). Developmentally appropriate practice in early childhood programs: Serving children from birth through age 8. 3rd Ed. Washington DC: National Association for the Education of Young Children.

Durand, T. (2010). Celebrating diversity in early care and education settings: Moving beyond the margins. Early Child Development and Care, 180(7), 835-848. doi: 10.1080/03004430802466226.

Eberly, J. L., Joshi, A., \& Konzal, J. (2007). Communicating with families across cultures: An investigation of teacher perceptions and practices. The School Community Journal, 17(2), $7-26$.

Epstein, A., \& Willhite, G. L. (2015). Teacher efficacy in an early childhood professional development school. International Electronic Journal of Elementary Education, 7(2), 189198.

Guo, K. (2015). Teacher knowledge, child interest and parent expectation: Factors influencing multicultural programs in an early childhood setting. Australian Journal of Early Childhood, 40(1), 63-70.

Gestwicki, C. (2007). Home, school, and community relations (6th ed.). New York: Thomson/Delmar. 
Gonzalez-Mena, J., \& Shareef, I. (2005). Discussing diverse perspectives on guidance. Young Children, 60(6), 34-38.

Grisham-Brown, J., \& Pretti-Frontczak, K. (2011). Assessing young children in inclusive settings: The blended practices approach. Baltimore, MD: Brookes.

Hauser-Cram, P., Sirin, S. R., \& Stipek, D. (2003). When teachers' and parents' values differ: Teacher ratings of academic competence in children from low-income families. Journal of Educational Psychology, 95(4), 813-820. doi: 10.1037/0022-0663.95.4.813

Knopf, H. T., \& Swick, K. J. (2007). Using our understanding of families to strengthen family involvement. Early Childhood Journal, 35(5), 419-427. doi: 10.1007/s10643-007-0198-z

MetLife, Inc. (2006). The MetLife survey of the American teacher, 2006: Expectations and experiences. New York: Metropolitan Life Insurance Company.

Mishel, L., Bivens, J., Gould. E., \& Shierholz, H. (2012). The State of Working America, 12th Edition. An Economic Policy Institute Book. Ithaca, NY: Cornell University Press

Montessori, M. (1923/1970). The child in the family. New York, NY: Avon Books.

Montessori, M. (1995). The child, society and the world. Unpublished speeches and writings. Oxford, England: Clio Press Ltd. (original German edition copyright 1979 by Verlag Herder)

Patton, M. (2015). The home visit: Creating connections \& building relationships with parents. Montessori Life, Spring, 42-43.

Reedy, C. K., \& McGrath, W. H. (2010). Can you hear me now? Staff-parent communication in child care centres. Early Child Development and Care (180)3, 347-357. doi: $10.1080 / 03004430801908418$

Summer, M., \& Summer, G. L. (2014). Creating family learning communities. Young Children, September, 8-14.

James, S., Brown, R. B., Goodsell, T. L., Stovall, J., \& Flaherty, J. (2010). Adapting to hard times: Family participation in local thrift economies. Family Relations, 59(4), 383-395.

Swick, K. (2004). Empowering parents, families, schools and communities during the early childhood years. Champaign, IL: Stipes.

Waldfogel, J., Craigie, T. A., \& Brooks-Gunn, J. (2010). Fragile families and child wellbeing. Future of Children, 20(2), 87-112.

Winterbottom, C. (2013). Voices of the minority: Japanese immigrant mothers' perceptions of preschools in the United States. Early Childhood Education Journal. 41:219-225.

Zygmunt-Fillwalk, E., \& Woods, A. (2007). Preparing teachers-empowering families. Childhood Education, (83)5, 308. 